\title{
Relationship between Adult Feeding and Emigration from Beans of Azuki Bean Weevil, Callosobruchus chinensis LinNÉ (Coleoptera: Bruchidae)
}

\author{
Kazutaka SHINODA ${ }^{1}$ and Toshiharu YoshIDA \\ Laboratory of Applied Entomology, Department of Agriculture, \\ Okayama University, Okayama 700, Japan
}

(Received October 26, 1983)

\begin{abstract}
The life history of the azuki bean weevil, Callosobruchus chinensis Linsé in the field, especially the process of weevil emigration from store to field has not been made clear. The mechanism of the emigration process was analyzed with specially designed apparatus in the laboratory. The presence of beans firmly suppressed emigratory activity in the first five days of adult life. The supplied diet (saccharose solution and yeast) moderately suppressed the emigratory activity, especially of older weevils. Males emigrated density-independently throughout their longevity, while females emigrated density-dependently until the fifth day and thereafter density-independently. Supply of the diet after different periods of starvation resulted in elongation of longevity and recovery of fecundity. When the diet was supplied on the first to third day after emergence, the total number of eggs and mean longevity were two and three times, respectively, as many as the control for whom no diet was supplied for adults. When diet was started on the fifth day, the fecundity in two days increased to the same level as when the diet was started just after emergence. The diet supplied adults nine days after emergence did not result in an increase of either fecundity or longevity.
\end{abstract}

\section{INTRODUCTION}

In Japan the azuki bean weevil, Callosobruchus chinensis (L.), is the most serious pest infesting azuki beans, Phaseolus angularis WRIGHT in storage. But the weevils have infested the beans in the field before they damage them in storage. In Okayama two varieties of azuki are planted, nathu-azuki and the more heavily planted aki-azuki. The akiazuki is planted in the middle of July and harvested between late October and early November. The authors observed that the weevils laid their eggs on the pods of the beans from middle September to late October, and the percentage of beans infested to the total number of beans harvested reached $15 \%$ at harvest when no insecticide was used.

The life history of the weevil in the field, however, has not yet been determined, especially the process of its emigration from storage to field, despite many investigations on its population biology by members of UTIDA's laboratory (UTIDA, 1943, 1971; IsHIDA, 1952; Yoshida, 1952; Nakamura, 1962; Nishigaki, 1963; Murai and FujiI, 1970; TAKAHASHI, 1976, among others). UMEYA (1966) analyzed the relationship between

1 Present address: Laboratory of Pest Control, Tōyō Sangyō, Shinyashiki-cho 3-19-20, Okayama 700, Japan 


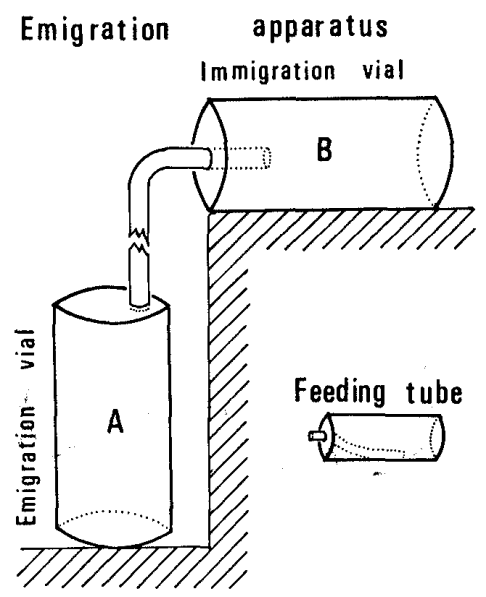

Fig. 1. Emigration apparatus and feeding tube.

emigration rate and weevil density with and without beans in experimental conditions and also in 1968, reported the results of an experiment on the effect of adult feeding on longevity and oviposition, but many questions remain to be answered about the weevil emigration.

In the present study the following four experiments were carried out to analyze the mechanism of the weevils emigration process from storage to field: (1) effect of diet supplied adults on the age-specific emigration rate, (2) effect of initial adult density on the successive daily emigration rate, (3) density effect on emigration of females at different ages and (4) effect of diet supply starting at different adult ages on longevity and oviposition.

\section{MATERIALS AND METHODS}

A culture of azuki bean weevil was started from eggs oviposited for $24 \mathrm{hr}$ by 500 pairs of one-day-old weevils on $500 \mathrm{~g}$ of azuki beans of $13 \%$ water content in a plastic case $(29 \times 19 \times 9 \mathrm{~cm})$ and was kept at $25^{\circ} \mathrm{C}, 70 \pm 5 \% \mathrm{RH}$.

For the experiment on emigratory activity, the emigration apparatus devised by PRUS (1963) was employed with some modifications (Fig. 1). Two glass vials $(5 \mathrm{~cm}$ inside diameter, height $11 \mathrm{~cm}$ ) and closed with a vinyl plug (5 $\mathrm{cm}$ diameter) were joined by a vinyl tube $(0.4 \mathrm{~cm}$ inside diameter, length $30 \mathrm{~cm})$. Adult weevils were released in a vertically placed vial (emigration vial, Fig. 1A) and permitted to emigrate to a horizontal vial (immigration vial, Fig. 1B). The tube was inserted into a hole made at the rim of the plug and projected $1 \mathrm{~mm}$ inside the emigration vial. In the immigration vial, the tube was inserted $5 \mathrm{~cm}$ into the center of the plug. The long $5 \mathrm{~cm}$ projection prevented the weevil from going back into the tube. Emigratory activity was judged by the number of weevils immigrating into the vial.

In some of the experiments, water or saccharose solution, $\mathrm{C}_{12} \mathrm{H}_{22} \mathrm{O}_{11}$, was supplied the weevil using a feeding tube laid on its side at the bottom of the emigration vial (Fig. 1). This tube was made of glass $(0.9 \mathrm{~cm}$ inside diameter, depth $3.5 \mathrm{~cm})$ in which a $3 \mathrm{~cm}$ length of thick cotton was inserted. The top of the cotton jutted out of the plug of the glass tube, so that the weevil could absorb the water or saccharose 
solution. Emigratory activity was tested in a dark condition to avoid the effect of light on weevil activity.

Experiments on age-specific emigration in the four conditions. Weevils 1, 3, 5, 7 and 9 days old were used in each experiment. The number of adults which dropped into and were caught in the emigration vial within $24 \mathrm{hr}$ after the release of adults of each age was counted and these are referred to as emigrants. Four different release conditions in the emigration vials were tested: (1) $8 \mathrm{~g}$ of fresh beans, (2) $2 \mathrm{ml}$ of water, (3) diet; $0.5 \mathrm{~g}$ of yeast and and $2 \mathrm{ml}$ of $5 \%$ saccharose solution and (4) no diet or beans. All tests started with the release of 8 weevils into a vial of each condition. The foregoing experiments were replicated ten times.

Experiments on the effect of initial density on emigration. The effect of adult density after the release of weevils aged less than $24 \mathrm{hr}$ on the succeeding daily emigration was tested using the initial density of $8,16,32,64,128$ and 256 weevils per $8 \mathrm{~g}$ of beans. The number of emigrants was counted at $24 \mathrm{hr}$ intervals throughout their longevity. As a control the same experiments were repeated without beans. Males and females were released separately. The experiments with 8,16 to 128 and 256 weevils were replicated ten, five and three times, respectively.

Experiments on the relationship between weevil density and emigration rate at different femal ages. Females less than $24 \mathrm{hr}$ of age were collected and maintained in a plastic case $(9.5 \mathrm{~cm}$ inside diameter, depth $5.5 \mathrm{~cm})$ at a density of $16,32,64,128$ and 256 weevils with beans until the day of each experiment: the first, third, fifth, seventh and ninth day after emergence. Emigration was tested at the density of 16 to 256 weevils per $8 \mathrm{~g}$ of fresh beans put in the emigration vial. When dead weevils were found, replacements of the same number and age were supplied from another case maintained at the same density as the experimental condition. Experiments of 16 to 128 and 256 weevils were replicated five and three times, respectively.

Experiments on the effect of adult diet-supply after starvation on longevity and fecundity. Twenty pairs of weevils less than $24 \mathrm{hr}$ after emergence were allowed to oviposit throughout their longevity on $20 \mathrm{~g}$ of beans in a plastic case $(9.5 \mathrm{~cm}$ inside diameter, depth $5.5 \mathrm{~cm}$ ). Groups of weevils were starved for $0,1,3,5,7$ and 9 days, respectively, and thereafter supplied $0.5 \mathrm{~g}$ of yeast and $2 \mathrm{ml}$ of $5 \%$ saccharose solution. The yeast, saccharose solution and beans were renewed every day. The number of eggs and dead adults were counted every day throughout their longevity. After each count, the dead adults were removed. The experiments were replicated five times.

\section{RESULTS}

\section{Age-specific emigration}

The results of the experiment on diet conditions in the emigration vial as they affected age-specific emigration are shown in Fig. 2 for males and females separately. In the control, without beans and no supply of water or diets (saccharose solution and yeast), both males and females showed a considerably high emigration rate with that of the females tending to be higher. The rate of both sexes increased as age advanced and the trend of the increase was more significant in the male. With fresh beans, almost all weevils of both sexes remained on the beans for the first five days and emigrated later. An increased eimgration rate was clearly recognized when water was supplied, especially in females, showing a very similar pattern with the control, although these 


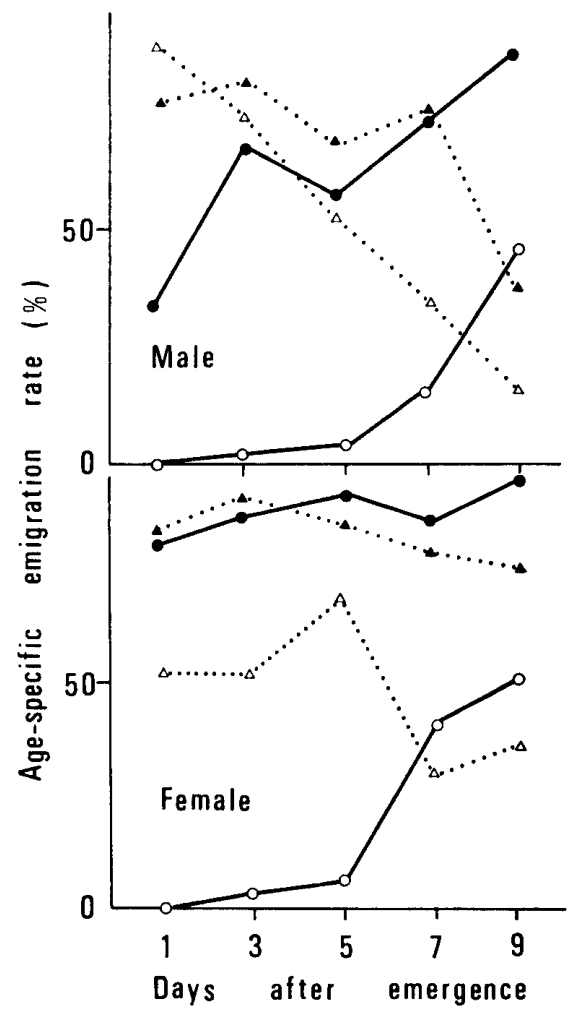

Fig. 2. Change of age-specific emigration rate as age advances under the different conditions: control (without beans and no diet or water supplied) $\boldsymbol{0}$, with beans $O$, water supplied $\boldsymbol{\Lambda}$, $5 \%$ of saccharose solution and $0.5 \mathrm{~g}$ of yeast supplied, $\triangle$. The age-specific emigration rate shows the percentage of the number of adults emigrating within $24 \mathrm{hr}$ after release each day to the number of released adults.

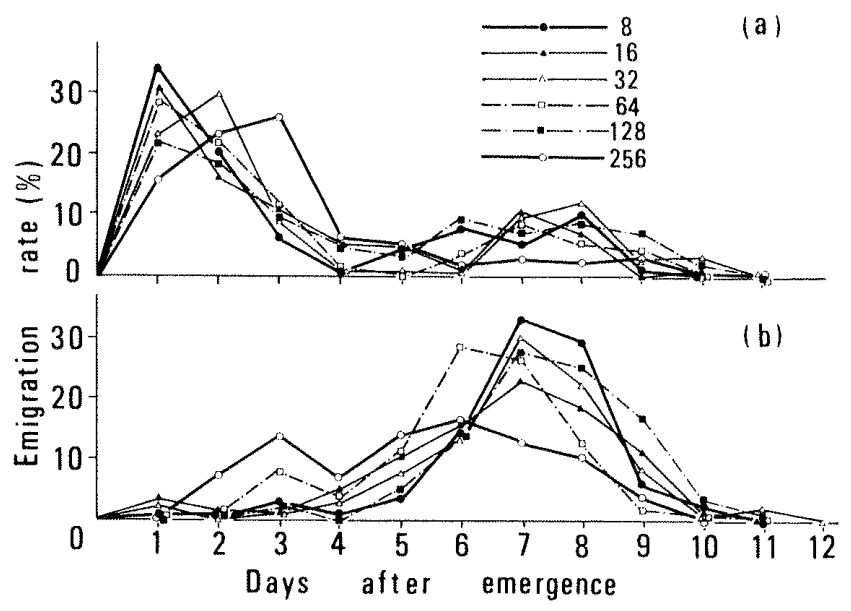

Fig. 3. Effect of the initial released density on the succeeding daily emigration rate in males: (a) without beans and (b) with beans. Emigration rate is shown as a percentage of the number of emigrants per day to the number of initially released weevils.

rates decreased as age advanced. The decreasing rate trend was more remarkable in the males. When diet was supplied for males, the emigration rate was high at the beginning and decreased steadly as age advanced. For females a rather uniform rate of $50 \%$ was maintained for the first five days and thereafter decreased considerably. Comparing these results with that of supplying water, it appeared that the availability of diet more definitely suppressed emigratory activity. The results suggest that the presence of beans suppressed the emigratory activity of young adults, while the diets suppressed that of older adults.

\section{Density effect on emigration rate}

The effect of initial weevil densities on successive daily emigration rates are shown in Figs. 3 and 4. In the males: without beans (Fig. 3 (a)), two peaks of emigration were found at all densities except for the 256 weevil density. The first peak lay during 


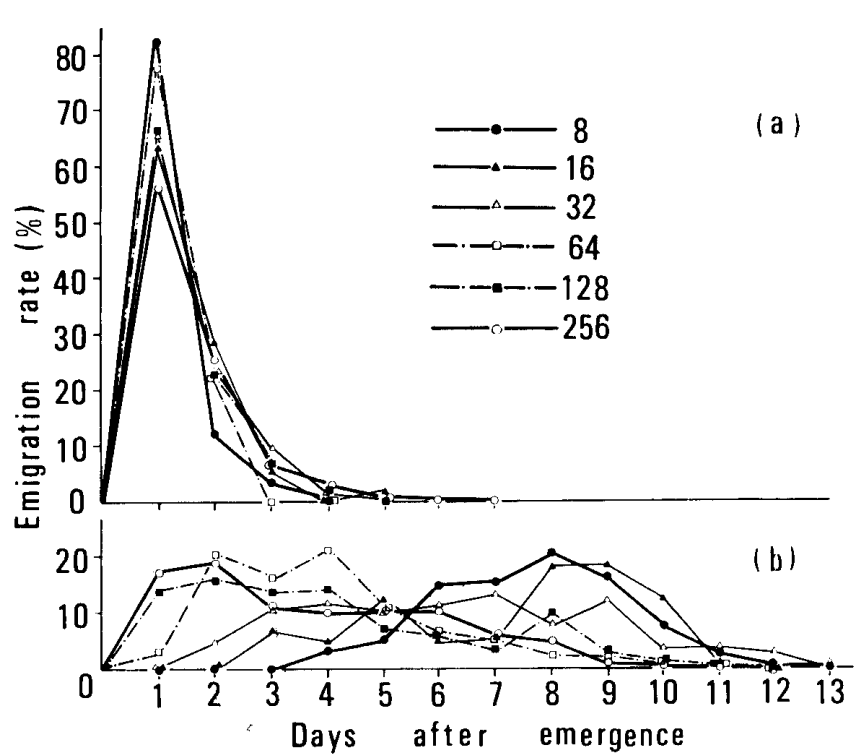

Fig. 4. Effect of the initially released density on the succeeding daily emigration rate in females: (a) without beans and (b) with beans. Emigration rate is the same as that in Fig. 3.

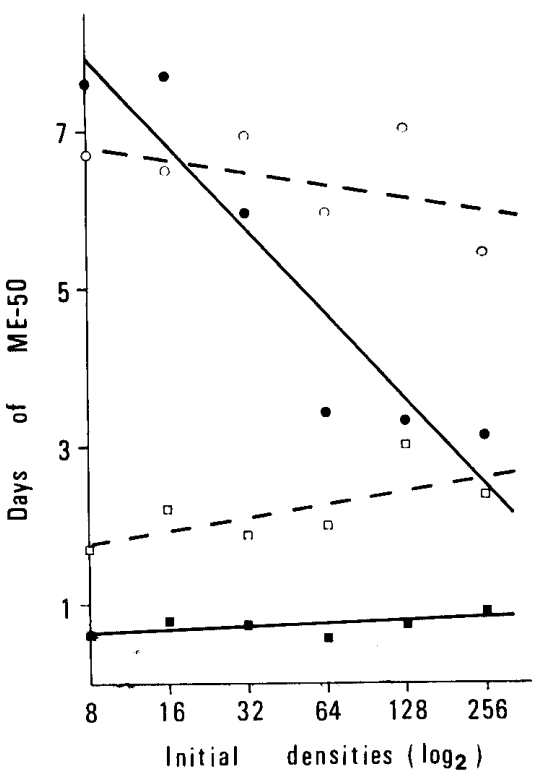

Fig. 5. Relationship between the initially released weevil density and the day when $50 \%$ of released adults had emigrated $(\mathrm{ME}=50)$. Male without beans $(\square)$ and with beans $(O)$, female without beans ( $\boldsymbol{\square})$ and with beans (-). Densities are shown on a $\log$ scale.

the first to third day and the second during the sixth to ninth day, although the earlier peaks were much higher at each density. With beans (Fig. 3 (b)), however, only one peak was found on the sixth or seventh day at all densities but the 256 weevil density. The emigration pattern at the 256 weevil density both with and without beans differed from that of other density classes because the adults interrupted each other's emigratory behavior. These results show that the presence of beans suppressed the emigratory activity of young males but not that of the older. In the females: without beans (Fig. 4 (a)), an extremely high emigration rate was observed on the first day at all densities and thereafter the number of emigrants decreased rapidly as age advanced. Most females had made their emigration by the fourth day. With beans, on the contrary, there was no such clear emigration (Fig. 4 (b)) although at low densities of 8 and 16 weevils the rate reached a peak later on the eighth to ninth day, while at high densities of 64 to 256 weevils it reached a peak the first to third day.

For a comparison of the emigration rates among the different experimental conditions (male or female, with or without beans), the day half the weevils, that is, $50 \%$ of the released adults, had completed their emigration was calculated from the results presented in Figs. 3 and 4 . The relationship between the initial densities of males or females and the days of $50 \%$ emigration is shown in Fig. 5. For males that day with beans was later than without beans at all densities. The days of half emigration with beans occurred earlier and those without beans later as the initial densities increased. For females, when beans were supplied, the number of days decreased sharply in propor- 
Table 1. Result of analysis of variance by two-way layout of the relationship between initial density and percentage of the total number of emigrants to the number of released adults

\begin{tabular}{lcccc} 
Source of variation & $\begin{array}{c}\text { Degrees of } \\
\text { freedom }\end{array}$ & $\begin{array}{c}\text { Sum of } \\
\text { sequences }\end{array}$ & $\begin{array}{c}\text { Unbiased } \\
\text { variation ratio }\end{array}$ & $\begin{array}{c}\text { F (variance } \\
\text { ratio 0.01) }\end{array}$ \\
\hline Density & 5 & 45.60 & 1.44 & 9.74 \\
Released condition & 3 & 57.63 & 3.03 & 26.87 \\
Error & 15 & 95.22 & & \\
Totals & 23 & 198.45 & & \\
\hline
\end{tabular}

a Released conditions (second row) consisted of four treatments: male only, female only, male with beans and female with beans.

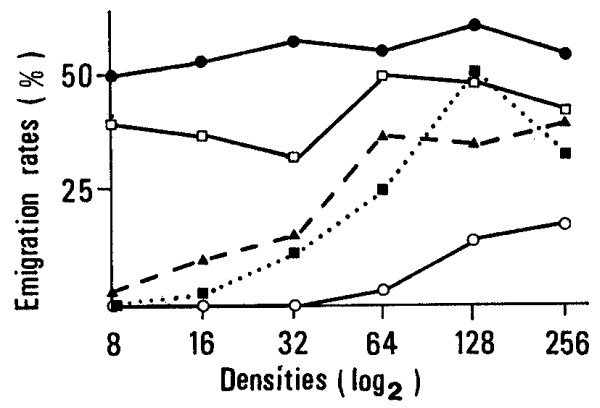

Fig. 6. Density effect at each different age on age-specific emigration. Age tested: 1 day (O), 3 days ( $\mathbf{\square})$, 5 days $(\Delta), 7$ days $(\square)$ and 9 days ( ) . The age-specific emigration rate is the same as that of in Fig. 2.

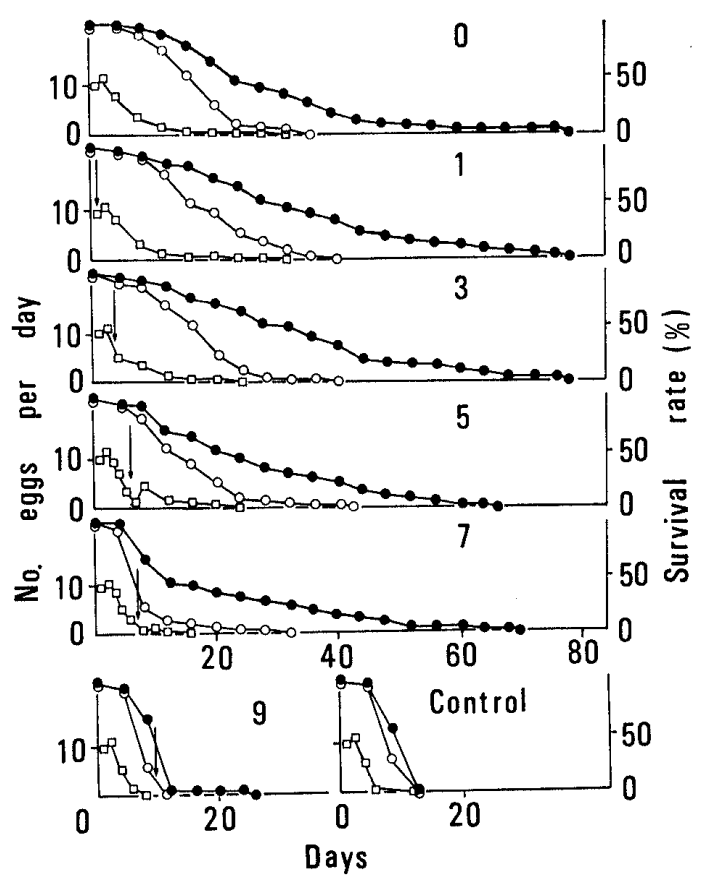

Fig. 7. Effect of diet supply $(0.5 \mathrm{~g}$ of yeast and $5 \%$ of saccharose solution) on survival rate (male - female $O$ ) and on no. of eggs per female per day ( $\square$ ). Arrows show the starting point of diet supply and numbers in the figures show the days starved.

tion to the increase of initial densities. These results show that the females emigrated density-dependently. On the other hand, the days without beans remained constant at about one regardless of released densities, earlier than that with beahs.

The relationship between the initial densities and the released conditions (male or female; with or without beans) on the emigration rate was studied by an analysis of variance by two-way layout using the results presented in Figs. 3 and 4; the result is shown in Table 1. More than $90 \%$ of the released weevils had emigrated at all densities by the end of each experiment and no significant differences were found among the 
Table 2. Population parameters when diet supply was started at different ages after emergence of azuki bean weevil

\begin{tabular}{|c|c|c|c|c|c|c|c|}
\hline \multirow{2}{*}{$\begin{array}{r}\text { Ages } \\
\text { (days) }\end{array}$} & \multicolumn{2}{|c|}{ Mean longevity (days) } & \multirow{2}{*}{$\begin{array}{c}\text { Total } \\
\text { number } \\
\text { of eggs }^{\text {a }}\end{array}$} & \multirow{2}{*}{$\begin{array}{l}\text { Oviposition } \\
\text { period } \\
\text { (days) }\end{array}$} & \multirow{2}{*}{$\begin{array}{l}\text { Net repro- } \\
\text { ductive rate }\end{array}$} & \multirow{2}{*}{$\begin{array}{c}\text { Innate } \\
\text { capacity } \\
\text { for increase }\end{array}$} & \multirow{2}{*}{$\begin{array}{l}\text { Generation } \\
\text { time (days) }\end{array}$} \\
\hline & Male & Female & & & & & \\
\hline $0^{\mathrm{b}}$ & 27.00 & 17.50 & 36.55 & 24.00 & 28.25 & 0.1190 & 35.00 \\
\hline 1 & 32.79 & 20.75 & 37.40 & 28.40 & 27.60 & 0.1173 & 40.00 \\
\hline 3 & 33.06 & 16.81 & 33.98 & 24.00 & 25.32 & 0.1146 & 39.00 \\
\hline 5 & 26.27 & 14.06 & 31.75 & 25.20 & 22.78 & 0.1130 & 41.00 \\
\hline 7 & 14.23 & 8.98 & 19.35 & 19.80 & 14.46 & 0.1013 & 33.00 \\
\hline 9 & 8.78 & 7.49 & 17.64 & 7.80 & 14.30 & 0.1004 & 11.00 \\
\hline Control $^{\mathrm{c}}$ & 8.55 & 8.15 & 18.10 & 7.70 & 14.50 & 0.1008 & 11.22 \\
\hline
\end{tabular}

a Number of female eggs per female.

b Diet supply was started from just after emergence.

c No food was supplied throughout longevity.

percentages in the four released conditions and densities at 0.01 level. These results suggest that neither initial density nor released condition affected the emigration rate and almost all of the weevils ultimately emigrated regardless of both initial density and the presence of beans.

\section{Relationship between density and emigration rate at different female ages}

Figure 6 shows the results of these experiments. Females aged one day emigrated density-dependently at high density, but did not emigrate at all at low density. Females aged one to five days emigrated density-dependently as the initial density increased. The emigration rates of females aged seven and nine days were always high at all densities and did not increase as the initial density increased, although that at nine days was higher than at seven days. Thus the females had two emigratory phases: one density-dependent younger ages, and the other age-specific and density-independent at older ages.

\section{Effect of diet supply to weevils of different ages on their fecundity and longevity}

As shown in Fig. 7, the effect of supplying diets after starvation resulted in the elongation of longevity and the recovery of fecundity. The longevity of both sexes when the diet was supplied immediately after emergence (top in the figure) was extended by three and two times, respectively, compared with that of control where no diet was supplied (bottom, right). The mean longevity when the diet began on the first to third day after emergence was the same as that when it was supplied immediately after emergence (upper three numbers in the figure). When the diet was supplied on the ninth day longevity was not extended with the exception of one instance. The diet supply had greater effect on male than on female longevity, although male longevity was as short as females when no diet was supplied them at all. When diet was supplied on the fifth day of emergence, it took two days for the weevils to recover their daily number of deposited eggs to the same level as that when the diet was supplied just after emergence. When the diet was supplied on the seventh day, egg deposits never recovered their original level but the oviposition period increased to more than two times that of control. However, the number of fecund weevils that could extend their oviposition period by the 
diet supply increased significantly in comparison with the control.

Population parameters calculated from Fig. 7 are shown in Table 2. The oviposition period, but not the longevity, was greatly extended by supplying the diet. Both the total number of eggs deposited and the oviposition period decreased as the diet supply was delayed. After the seventh day, no remarkable increase of fecundity was expected by supplying the diet. The mean generation time was more than 33 days when diet supply was started from the first to seventh day. On the other hand, when the food supply began on the ninth day, the mean generation time was the same as the control where no diet was supplied. The net reproductive rate and the innate capacity for increase decreased with the delay in the start of supplying diet and this decrease became greater after the seventh day.

\section{DISCUSSION}

Factor affecting the emigratory activity of both males and females changed on the fifth day after emergence (Figs. 2-4 and 6). The age-specific emigratory activity was suppressed by supplying azuki beans in the emigration vial until the fifth day and thereafter was not suppressed by the presence of beans, but by a supplied diet of saccharose solution and yeast (Fig. 2). The results suggest that the azuki bean weevils less than five days old tend to emigrate to search for beans on which a male and female mates and on which the female can oviposit; weevils older than five days emigrate to search for a new diet source.

The azuki bean weevil is sexually mature at emergence and ready to mate and oviposit. These abilities are maintained for the first five days after emergence and thereafter are lost (Nishigaki, 1963). The age when sexual ability is lost corresponds with the age when the emigratory tendency changes. When the weevils have sexual ability, their emigratory activity is suppressed by the presence of beans that offer both a mating place and an oviposition place. When they lose their sexual ability, the presence of beans no longer exerts such a strong effect and the weevils emigrate to search for food unless diet is supplied. This tendency may have deep significance in their life history.

The density effect on male emigration was different from that of female; the male emigrated density-independently (Figs. 3 and 5). This tendency has significance in the maintenance of the population because it affects mating. The male azuki bean weevil emerges one or two days earlier than the female as is true of many other insects. It has been reported that the earlier emergence of the male incre ases the mating possibilities (Wiklund and Fagerstrom, 1977). Newly emerged females have a sharp densitydependent emigration tendency when food is not supplied but beans are, so the males have to mate with them as soon as possible. For that reason the density-independent emigratory tendency is considered more favorable for increased mating possibilities than the density-dependent one. Therefore, not only the earlier male emergence, but also the male tendency for density-independent emigration favors increased mating possibilities.

The female emigration pattern changed from density-dependent to density-independent emigration with age. This change of pattern is related to the change of oviposition ability. Young females emigrated density-dependently because they tended to avoid beans which they had conditioned especially at high densities (Yoshida, 1961). 
Old females who had lost their oviposition ability emigrated density-independently to search for food since there was no food on the stored beans. Both these density-dependent and -independent emigrations seem to favor population regulation. At a low density young females stayed on the beans and continued to lay their eggs until they lost their oviposition ability; then the number of progeny was expected to increase. At high density while they had their oviposition ability young females emigrated densitydependently. Thus the number of eggs laid on beans at the place of emergence decreased and an additional chance for oviposition was given at the new habitat to which they emigrated. In this manner the number of progeny is thought to be regulated density-dependently. Nakamura (1962) showed that the population balance of the azuki bean weevil was maintained by artificially removing and adding adults in an experimental population that imitated the results of emigration and immigration. UMEYA (1966) concluded that emigration did not favor population maintenance when he compared the number of emerged adults from an open population cage in which emigration was permitted with that from a closed cage in which emigration was prohibited. UMEYA's results were obtained at a low density of 15 or 30 pairs per $20 \mathrm{~g}$ of beans. Under these densities weevils should not emigrate until they have lost their oviposition ability and all their eggs are laid on bean there, so differences in the number of newly emerged adults might not have been detected between the open and closed cages.

Next, the relationship between adult feeding and emigration is considered in connection with the life history of the weevil. Emigration after the loss of sexual ability seems not to favor the maintenance of the population. In the present study feeding after the loss of sexual ability was found to recover oviposition ability and to extend weevil longevity. The insects emigrating from store to field, therefore, seem to take food outdoors, extending their longevity, recovering their sexual ability and are able to colonize in a new habitat.

Related results have been reported on some Bruchids: Callosobruchus chinensis (L.) and Zabrotus subfacitus (UMEYA, 1968), C. maculatus (LARson and Fisher, 1924; UMEYA, 1968), and Acanthoselides obtectus (Leror, 1978).

LinsLey (1944) reported the natural sources of insects associated with stored food products and classified the insects according to their sources. He gave seed-infesting species as an example. Three groups were recognized corresponding to three steps in the process of becoming a pest; the first group is monovoltine species such as Bruchus pisorum which can deposit eggs only on the pod of legumes in the field and develop on dried beans in store, the second group is multivoltine spceis such as Callosobruchus chinensis which attacks the pod in the field and is also capable of continuing to breed in the dried beans in store, and the third group is multivoltine species such as Sitophilus granaris which remain in storage throughout the year (Yoshida, 1958; among others). Species in the second group can maintain their population without adult feeding in store, though they sometimes feed on food such as fungi (SinHa, 1971). But these weevils are liable to consume all beans in store in a few generations, when their breeding conditions are favorable, for they have a high innate capacity for increase and cannot help emigrating from store to field. UMEYA (1968) considered that weevils emigrating from store to field had to take food and extend their longevity in order to continue the generation, since suitable legume pods were not continuously supplied in the field. The results obtained in the present study support his views. In addition, the authors observed that 
the azuki bean weevil fed on the pollen of chrysanthemum and conidia of the powdery mildew, Erysiphe piside CANDolle, on azuki bean leaves in the field. Other related observations on adult feeding of Bruchid have been reported: Callosobruchus chinensis on marguerite flower (UMEYA, 1981) and on cajanus flowers (Williams, 1977), C. maculatus on cotton flowers (AsHmeAD, 1894) and Acanthoserides pauperculus on various flowers (Johnson, 1977).

\section{REFERENCES}

Ashmead, W. H. (1894) Notes on cotton insects found in Mississippi. Insect life 7: 240-247.

IshidA, H. (1952) Studied on the density effect and the extent of available space in the experimental population of the azuki bean weevil. Res. Popul. Ecol. 1: 25-35.

Johnson, C. D. (1977) Notes on the host plants and distribution of Acanthoscerides pauperculus (Coleopt. Bruchidae). Pan-Pacific Entomol. 53: 303-304.

Larson, A. O. and C. K. Fisher (1924) Longevity and fecundity of Bruchus quadrimaculatus FAB. as influenced by different foods. J. Agric. Res. 29: 297-305.

Leror, B. (1978) Alimentation des adultes d'Acanthoscelides obtectus (Coleoptere, Bruchidae): Influence sur la longévité et la production ovarienne des individus vierges. Ann. Zool. Ecol. Anim. 10 (4): 559-567.

Linsley, E. G. (1944) Natural sources, habitats and reservoirs of insects associated with stored food products. Hilgardia 16: 187-224.

Murai, M. and K. FujII (1970) Examination of the influence of density pressure on the pattern of adult emergence with reference to the azuki bean weevil, Callosobruchus chinensis. Res. Popul. Ecol. 12: 219232.

Nakamura, H. (1962) The experimental demonstration of population balance in the azuki bean weevil, by removing and adding. Jap. J. Ecol. 12: 141-146.

Nishigaki, J. (1963) The effect of low population density on the mating chance and the fecundity of the azuki bean weevil, Callosobruchus chinensis L. Jap. J. Ecol. 13(5): 178-184.

PRUs, T. (1963) Search for methods to investigate mobility in Tribolium. Ecology 44: 801-803.

Sinha, R. N. (1971) Fungus as food for some stored-product insects. J. Econ. Entomol. 64: 3-6.

TAKahashi, F. (1976) Reproduction curve in the experimental population of Callosobruchus chinensis. Physiol. Ecol. Japan. 17: 495-501.

UMEYA, K. (1966) Studies on the comparative ecology of bean weevils. II. An interspecific comparison of the escaping behaviors of adult and the reproduction ratio in a semi-open cage. Res. Plant Prot. 4: $1-15$.

UMEYA, K. (1968) Studies on the comparative ecology of bean weevils. III. Effect of feeding on the life span and oviposition of the adult of three species of bean weevils. Res. Plant Prot. 5: 39-49.

UMEYA, K. (1981) Biology of bruchids-Life span of the adults. Insectarium 18 (7): 16-23.

UTIDA, S. (1943) Studies on experimental population of the azuki bean weevil, Callosobruchus chinensis: IX. General considerations and summary of the serial reports from I to III. Mem. Coll. Agr. Kyoto Imp. Univ. 54: 23-40.

UTIDA, S. (1971) Influence of temperature on the number of eggs, mortality and development of several species of Bruchid infesting stored beans. Jap. J. appl. Ent. Zool. 15: 23-30.

Wiklund, C. H. and T. FAgerstrom (1977) Why do males emerge before females? A hypothesis to explain the incidence of protandry in butterflies. Oecologia 31 (2) : 201-214.

Williams, I. H. (1977) Behaviour of insects foraging on pigeon pea (Cajanus cajan) in India. Trop. Agric. 54: 353-363.

Yoshida, T. (1952) Experimental analysis of emergency curve. Res. Popul. Ecol. 1 : 152-165.

YoshidA, T. (1958) Origin and evolution of the insects infesting stored products. Biol. Sci. 10: 60-68.

Yoshida, T. (1961) Oviposition behaviors of two species of bean weevils and interspecific competition between them. Mem. Fac. Lib. Art Educ., Nat. Sci., Miyazaki Univ. 11: 41-65. 